Open Access

\title{
Motivation and attitude towards shadowing: learners perspectives in Japanese as a foreign language
}

Hideki Sumiyoshi ${ }^{1,2^{*}}$ and Chavalin Svetanant ${ }^{1}$

\author{
* Correspondence: \\ hideki.sumiyoshi@students.mq.edu.au \\ ${ }^{1}$ Department of International \\ Studies, Macquarie University, North \\ Ryde, Australia \\ ${ }^{2}$ Macquarie University, North Ryde, \\ NSW 2109, Australia
}

\begin{abstract}
Shadowing has increasingly been recognized as an effective practice for developing listening skills in second language learning. However, there is very little study focusing on learners' psychological aspects in implementing shadowing practice. The aim of this study is to explore second language learners' psychological factors, from the motivation framework point of view, in relation to shadowing practice in Japanese as a foreign language context. This study addresses research questions regarding: (1) perceived effectiveness of shadowing; (2) differences in perception depending on the shadowing performance skills; (3) factors that encourage continuing of shadowing; and (4) perceived positive and negative aspects of shadowing. The participants were 36 university students who were enrolled in an advanced Japanese language unit at an Australian university. They were asked to complete a written survey containing 35 questionnaire items and 3 open-ended questions at the end of the study period. The study employs mixed methods, of quantitative and qualitative approaches, to analyze the results and findings. The results indicate that the majority of participants perceive shadowing as effective for both listening and speaking skills, and agree on the usefulness of feedback. However, individual differences were found in how they favor the shadowing speed in relation to their comprehension of the content. The implication of classroom applications is also discussed.
\end{abstract}

Keywords: Second language learning, Japanese, Shadowing, Motivation

\section{Introduction}

In the field of second language acquisition (SLA), a teaching technique known as 'shadowing' has increasingly been recognized as an effective practice for developing listening skills in Japan. Shadowing refers to an auditory tracking task of simultaneous repetition of heard native speech through a headphone set (Lambert 1992); which had been originally used as a training method for simultaneous interpreters, as it requires a high competency of both listening and speaking skills occurring at the same time. This act of simultaneous listening and speaking is not only unique to shadowing, but often occurs in our daily lives in a form of inner voice, or sub-vocalization, in the phonological loop of working memory in the brain (Baddeley 1992). This sub-vocalization typically occurs when thinking aloud, repeating the interlocutor's speech in mind, or even reading a book to process the linguistic information inside the brain. This

(c) The Author(s). 2017 Open Access This article is distributed under the terms of the Creative Commons Attribution 4.0 International License (http://creativecommons.org/licenses/by/4.0/), which permits unrestricted use, distribution, and reproduction in any medium, provided you give appropriate credit to the original author(s) and the source, provide a link to the Creative Commons license, and indicate if changes were made. 
sub-vocalization is the very key feature of the shadowing technique since it activates high level of intended attention in the working memory. Tamai (1997), the pioneer of shadowing research in Japan's English as a foreign language (EFL) context, re-defined Lambert's definition of shadowing as a training technique of listening which the learner attempts to repeat the incoming information simultaneously as exactly as possible while listening attentively to the heard speech (pp. 105-106).

Tamai (1992) found statistical significance that shadowing was more effective than dictation. Led by Tamai's study, there has seen a rise in popularity of shadowing practice as a L2 teaching technique in Japan. The effectiveness of shadowing has been proven in a number of researches in the EFL context (Hamada 2011a, 2016; Shiki et al. 2010; Tamai 1997), and by some studies in the Japanese as a second language (JSL) context (Kurata 2007; Mochizuki 2006; Toda et al. 2012). The effect of shadowing is attributed to the stimuli of working memory during the attempt of on-line brain activity (simultaneous listening and speaking), which encourages automatization of the bottomup language processing (Kadota 2007, 2012). However, Kadota contends that it is a highly cognitive activity, which requires careful consideration by practitioners when implemented as a pedagogical tool in language classroom teaching. The mechanical characteristic of shadowing practice has been considered suited to Japan's EFL context, since this context is mostly based on grammar-translation method and is a memorization-centered pedagogical culture (Sasaki 2007); which is why shadowing has won popularity in Japan's L2 learning context.

On the other hand, this suggests possible difficulties in implementing shadowing in a different L2 context, outside Japan, such as in an English speaking context such as Australia in the present study. According to Markee's (1992) framework for innovation in language teaching, the mechanical routine work of shadowing would potentially trigger resistance in employing shadowing practice outside Japan, since the quality of teaching can be more harmful than beneficial (p. 233); largely due to differences in comparison to the L2 pedagogical mainstream of communicative language teaching, where learners' creative language output is mostly emphasized (Hamada 2015, p.9). In addition, the audiolingual aspect of shadowing practice can also lead to learners' anxiety, such as speech apprehension, test anxiety, and fear of negative evaluation, because shadowing requires learners to output speech in exactly the same manner as in the model audio, in front of an audience in class (Horwitz et al. 1986).

Taking into consideration these concerns in implementing shadowing in language classes at an Australian university, for the present study, it was decided to conduct shadowing as a homework assessment so that students could fully concentrate on the input of the model audio with a minimum of interference to his/her own output, which is expected to bring positive side effects in alleviating speech apprehension and fear of evaluation in front of the teacher and peers.

\section{Theoretical background}

Motivation is of crucial importance in language learning. It is widely accepted that learners who are motivated are more likely to achieve the learning outcomes than those who are not. In this section, we will explore a variety of motivation theories in the domain of SLA, to build a theoretical framework for the upcoming empirical analysis. 
Motivation is a multifaceted construct and involves attitudinal component which is a strong predictor towards language learning because attitudes directly influence learners' behavior towards achivement (Gardner 1985). In his Socio-Educational Model, Gardner explains motivation in L2 learning as a dichotomy between integrative motive and instrumental orientations (ibid, p. 51). Figure 1 illustrates his more recent version of the model (Gardner 2001, p.4). The central concept of this model is motivation, that is directly influenced by integrativeness and attitudes toward the learning situation (shown by the direction arrows), which all together form integrative motivation. Language aptitude is the other determinant of language achievement, among other support and other factors, which are assumed to involve instrumental motives.

Out of this integrative-instrumental dichotomy, integrative motivation is the most important driver of motivation, since "one complex that seems particularly involved in second language learning was best identified as an integrative motive" (Gardner 1985, p. 56). However, Gardner's Socio-Educational model is based on a specific social and cultural context, namely the French-speaking community in Canada, where integrativeness and attitude toward the learning situation reflect genuine interests in the French/ English bilingual community. Therefore, this model is considered not very applicable to the context of this study, where the target L2 community has much less to do with the learners of Japanese language in an Australian university.

In elaborating the external factors for integrative motivation, Deci et al. (1991) propose self-determination theory, which involves a motivated process of internalization, through a continuum from extrinsic towards intrinsic motivation (pp. 328-330). The main focus is on the elaboration of extrinsic motivation in four categories, based on the relationship between the external factors and the degree of self-determination.

Figure 2 presents a visual continuum of self-determination theory, arranged from left to right, from non-self-determined to the most self-determined, in terms of the degree to which the individual is motivated in the behaviour. The far left is the newly added category, amotivation, which is the state of lacking an intention to act (Ryan and Deci 2000).

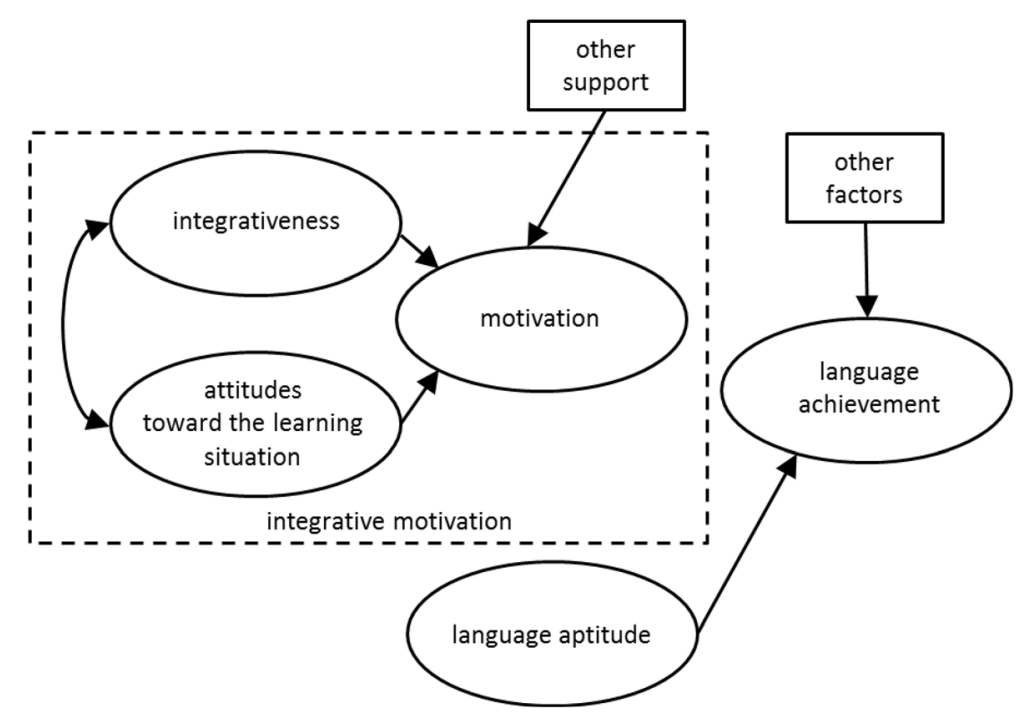

Fig. 1 Socio-Educational Model of Second Language Acquisition (Gardner 2001) 


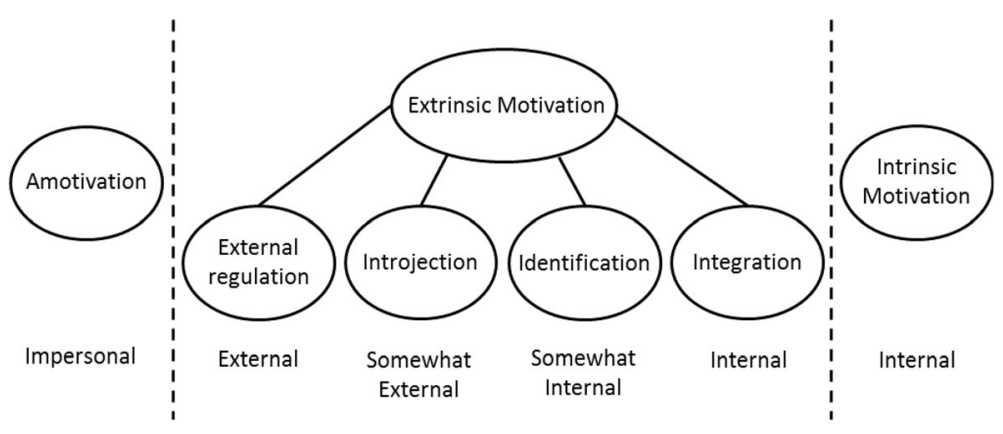

Fig. 2 A Taxonomy of Human Motivation, adopted from Ryan and Deci (2000)

In the middle block is extrinsic motivation, which is divided into four categories: external regulation, the least self-determined form of extrinsic motivation (e.g. performance due to reward, threat, or to avoid punishment); introjected regulation, involving behaviours incorporating others (e.g. actions in order to impress others, or with the feeling of pressure or guilt); identification, involving behaviour based on personal belief of worthiness or usefulness (e.g. willing to memorize vocabulary because it is relevant for reading); and integrated regulation, which is similar to intrinsic motivation but not for enjoyment or for interest (e.g. reading a newspaper in L2 because it is a good exercise to improve the target language). The far right end is intrinsic motivation, in which the learner is inherently interested in and enjoys the activity. Intrinsic motivation and extrinsic motivation are fundamentally different from each other, in that they are not mutually transformable (Ryan and Deci 2000, pp. 61-62). This intrinsic motivation is the primary motivator towards L2 learning, which is equivalent to Gardner's integrative motivation; however, intrinsic motivation is more universal than integrative motivation, because it concerns the target language itself but not the community in which the language is used. For instance, L2 learners are likely to find intrinsic motivation in shadowing, because the activity itself provides realistic use of their target language; but will not necessarily find integrative motivation, because shadowing practice is fundamentally self-completed, and does not necessarily involve interaction with the target community.

Vallerand (1997) further develops and proposes a three-part taxonomy for intrinsic motivation (Watanabe, Oba, Sugiyama, Nohara, \& Sakuta 2013): IM-Knowledge is the motivation associated with gaining new ideas and knowledge; IM-Accomplishments relates to the feelings of trying to master the task or achieve the goal; and IM-Stimulation refers to pleasant sensations or enjoyment through performing the task (p. 285). The commonality of these IMs is the pleasant experiences in conducting the task and challenges. Vallerand's IM taxonomy is a significant leap from the traditional integrative/intrinsic motivation, in that IM is not viewed as static trait of L2 learners, such as for inherent interests in the target community or the language itself, but a sequence of sensations/feelings towards certain tasks: that motivation has momentum fluctuations of ups and downs.

This view is common to Dörnyei's (2002) task motivation, in terms of viewing motivation as temporal than static. Dörnyei's model is divided in three phases with different motives: the first stage is called choice motivation, where motivation has to be generated; followed by the second stage, executive motivation, which relates to the generated 
motivation needing to be actively maintained; and the final stage is termed motivational retrospection, as the learner will determine the kind of activities to pursue in the future depending on the retrospective self-evaluation of the task (Dörnyei 2002, p. 140). For example, in the shadowing homework task in the present study, it is the student who decides when and how much to practice (choice motivation), and so also the goal setting as to when to complete the task (executive motivation); then s/he will determine whether the efforts put into the task have been worthwhile, after receiving the feedback (motivational retrospection), which becomes the main source for deciding whether $\mathrm{s} / \mathrm{he}$ is willing to continue the task in the future. Therefore, this task motivation model is specific to curriculum design; and the teachers' decisions on what activity to conduct becomes crucial, because if a student received negative self-evaluation after the task, s/he would not be willing to conduct the same type of activity again. On the contrary, the task motivation model assumes that students will most likely continue the activity if the first two task motivation phases proceed successfully, resulting in positive motivational retrospection even if the task requires excessive effort from the students.

Dörnyei (2009) further proposed the newest theoretical model in L2 motivation research today, the L2 Motivational Self System, which consists of the following three components: Ideal L2 Self, Ought-to L2 Self, and L2 Learning Experience. The first component refers to the imaginary L2 speaker that the learner perceives as ideal (the person s/he wishes to become). Dörnyei explains that the Ideal L2 Self "is the powerful motivator to learn the L2 because of the desire to reduce the discrepancy between our actual and ideal selves" (ibid, p. 29); which component corresponds to the integrative and instrumental motives. The second one, Ought-to L2 Self, is related to the attributes that one perceives s/he ought to have, in order to satisfy expectations and to avoid negative outcomes; which is equivalent to more extrinsic types of instrumental motives. Finally, L2 Learning Experience refers to the immediate learning environment and experience (ibid, p. 29). The Ideal L2 Self contributes in a positive manner if it is perceived to be manageable and realistic. On the other hand, it may behave otherwise if the ideal self appears too distant or unrealistic. However, even if it appears distant, it is of vital importance for the learners to see the path towards the ideal self with clear vision, so that they can move forward in concrete steps. Shadowing model material is a good example of this, able to play a role as a 'powerful motivator', since the goal is set by native speech, which most L2 learners undoubtedly perceive as ideal. This is, indeed, for a practical reason, limiting the scope of shadowing assessment criteria within the accuracy against the literal text (and not prosodic features such as pronunciation, intonation, fluency, etc.), in order to maintain objectivity in the marking scores; however, this goal setting as an assessment task enables students to set a realistic Ideal L2 Self, and detailed feedback of their shadowing performance is expected to provide a concrete picture of discrepancy between the present self and the ideal self. It is also expected, on the other hand, that Ought-to L2 Self may invite negative effects for those who are not proficient in shadowing performance, because they may emphasize the distance between the present and the ideal self. Therefore, in applying the L2 Motivational Self System to shadowing, it is best to provide materials that are within proximal range for the learners, so that they can see moderate discrepancy between their performance and Ideal L2 Self. 
The main objective of the present study is to investigate the influences of shadowing on L2 learners' psychological factors, from the motivation framework point of view. It is considered crucial to investigate the sources that encourage learners' intention to continue shadowing, in order to improve the implementation of shadowing in JFL context. Therefore, in this study, the afore-mentioned motivation frameworks will be applied specifically for this shadowing study in constructing survey questionnaires, in order to investigate the following research questions:

1. Is shadowing considered effective by the participants?

2. Is there a difference in learners' attitude/motivation towards continuing shadowing, depending on their shadowing performance skills?

3. What are the influential factors that encourage participants to continue shadowing in the future?

4. What are positive and negative aspects of shadowing perceived by the participants?

\section{Methods}

\section{Participants}

The target participants of this study were Australian university students who were enrolled in an advanced-level Japanese language unit. Since shadowing practice and other listening-related tasks were part of the unit assessment, it was compulsory that students complete those tasks as unit requirements. However, students were told that their participation in this study was voluntary, and their decision would not affect their grades. They were asked to sign the consent form and answer a 3-page survey on the last day of the semester. Since the instructor and the author of this study is the same person, another teaching staff member collected these documents on behalf of the author. This procedure was approved by the university's Ethics Committee. Out of 43 enrolled students, 36 agreed to participate in this study. There are more females $(n=25)$ than males $(n=11)$, and all of them were between 18 and 24 years old. The majority of the participants were majoring in Japanese $(n=28)$, and more than half spoke English as a native language $(n=21)$, while other native languages included Chinese $(n=11)$, Korean $(n=2)$, and others $(n=2)$. With regard to previous experience in shadowing practice before this study, one third of the participants had experienced shadowing in the previous semester as a unit assessment, while two-thirds $(n=24)$ had never engaged in shadowing before this study.

\section{Shadowing materials}

In implementing shadowing practice in the second language teaching context, Kadota and Tamai (Kadota and Tamai 2004) recommend the following six shadowing steps: 1) listening: listening to the audio without the script, and trying to roughly grasp the content and the speech style; 2) mumbling: shadowing without the script, focusing on the heard sound rather than reproducing pronunciation; 3) synchronized reading (content understanding): shadowing with the script, focusing on the meaning of the script; 4) prosody shadowing: shadowing focusing on prosodic features, such as stress, rhythm, intonation, speed, and pause; 5) synchronized reading (difficult points): shadowing with the script, focusing on the parts listeners find difficult; and 6) content shadowing: 
shadowing focusing on the content without reading the script (p. 62). This set of shadowing steps has been widely referred to by teachers and researchers (Hamada 2012; Kyo 2012; Saito et al. 2011, etc). It is suggested that the level of shadowing script ideally should include 2 or 3 unknown vocabulary items in every 100 words; and that it be presented at the speed that learners can listen and grasp the general meaning, which is the proximal level of i-1, where they can feel comfortable in shadowing (Kadota 2007, p. 236). This recommended difficulty assumes content shadowing, the final shadowing step focusing on the understanding of the content meaning, in that it limits the least number of unfamiliar words, at moderate speech speed. However, the shadowing materials for the present study were developed in order to target the mastery of prosodic shadowing, focusing on the accuracy of the speech production. Therefore, the shadowing materials in this study included more than a few unknown vocabulary and grammar expressions; while the degree of unfamiliarity may largely vary depending on the language proficiency level of each student. As for the shadowing model audio speed, gradual speed progression method was employed. The main purpose of this method is to ascertain that all the students have become familiar with shadowing practice at relatively slow speed, and then to gradually adjust them to the moderate and then faster speed on a weekly basis, with the aim to be at a native-like speed at the end of the study period. In doing so, instead of using commercial audio materials (e.g. textbook $\mathrm{CDs}$ ), the teaching instructor, who is a native Japanese speaker, recorded the model audio himself, in order to flexibly adjust the speech speed to suit best this study design.

\section{Shadowing feedback}

In conducting shadowing, the assessment criteria were placed on the accuracy against the literal text out of $100 \%$, where each mistake was highlighted and corrected above the kana script on the printed feedback sheet, to be returned to students in the following class period. Students were instructed to repeat the week's shadowing material at least six times before recording their shadowing performance, in order to reach their maximum reproduction rate; according to Shiki et al.'s (2010) study result of ceiling effect in shadowing practice of 4 to 5 trials (p. 90). The shadowing-as-homework practice in the present study also contributes in alleviating the aforementioned, Horowitz's test anxiety, because students can re-take their recordings until they become satisfied with their shadowing performance. In Aida's (1994) study of foreign language anxiety in the JFL context, she found that test anxiety was not a contributing factor among American university students, who were enrolled in the second-year Japanese language unit. This finding is consistent with MacIntyre and Gardner's (1991) suggestion that, "as experience and proficiency increase, anxiety declines in a fairly consistent manner" (p. 111). It is reasonable to assume, as far as shadowing-as-homework is concerned, that students are least likely to feel anxious with this activity, even though it is of a listening and speaking nature.

\section{Survey questionnaires}

The survey consisted of three parts: demographic information on the first page; questionnaire items on the second page; and open-ended questions on the third page (see Additional file 1). The questions in the second part were designed to gather information related to the constructs of the following areas, containing 5 questions in each 
category: (1) perception of improvement in listening and speaking (Spiller, Daro, BFabbro, \& Bosatra 1990); (2) attitude towards shadowing performance (Pf) and satisfaction (St); (3) intrinsic motivation (Watanabe et al. 2013) and extrinsic motivation (EM); and (4) cost (Ct). The total 35 items were randomly shuffled, and rearranged manually where questions in the same category continued in succession. These items used a six-point Likert-scale, with 6 indicating 'Strongly Agree', 5 'Agree', 4 'Partially Agree', 3 'Partially Disagree', 2 'Disagree', and 1 'Strongly Disagree'. The reason for employing the six-point instead of five-point scale was that the results were expected to present more detailed affirmative/negative orientation if participants were asked to choose whether they 'Agree' or 'Disagree', instead of choosing a neutral answer such as 'not applicable' or 'don't know'.

In constructing questionnaire items for 'motivation', Pintrich et al.'s (1991) Motivation Strategies for Learning Questionnaire (MSLQ) was considered a suitable reference for the present study, because it is widely applicable in the field of educational psychology, and aimed at university students. In addition, its self-reporting items constitute general descriptions rather than specific behaviors (Tseng et al. 2006). The selected items were modified and paraphrased specifically to suit shadowing practice. With regard to the items for 'cost', Hamada's (2011b) questionnaire items were referred to and modified according to the shadowing conducted in the present study. The other items ('improvement' and 'attitude') were constructed by taking the actual shadowing conduct into consideration, such as returning detailed feedback, speed progression, and the like.

\section{Data analysis}

a) To check the reliability of the second part of the questionnaire, the Cronbach alpha test was used to measure internal consistency for each category.

b) To address Research Question 1, frequencies and percentages of participants' responses to the questionnaires were calculated. In doing this, the categories of 'Strongly Agree' and 'Agree' were merged, and so were 'Strongly Disagree' and 'Disagree', while 'Partially Agree' and 'Partially Disagree' remained separate, in order to make clear whether there was a positive or negative orientation toward the questionnaire items.

c) Exploratory factor analysis was performed in order to investigate possible common trends across the questionnaire items.

d) In addressing Research Question 2, participants were divided into two groups, of higher shadowing proficiency and lower proficiency, based on the average shadowing scores throughout the study period. In order to measure the degree of relationship with the questionnaire item of the intention to continue shadowing after this study (item Sf4, see Table 1), Pearson's correlation coefficients were calculated with Sf4 as the dependent variable.

e) Scatter diagrams were generated to project visual mapping of the relationship between correlation values to the item Sf4 and mean item scores, to identify variables that needed to improve in order to encourage the intention to continue shadowing for Research Question 3.

f) Qualitative analysis was conducted for open-ended questions to explore Research Question 4. 


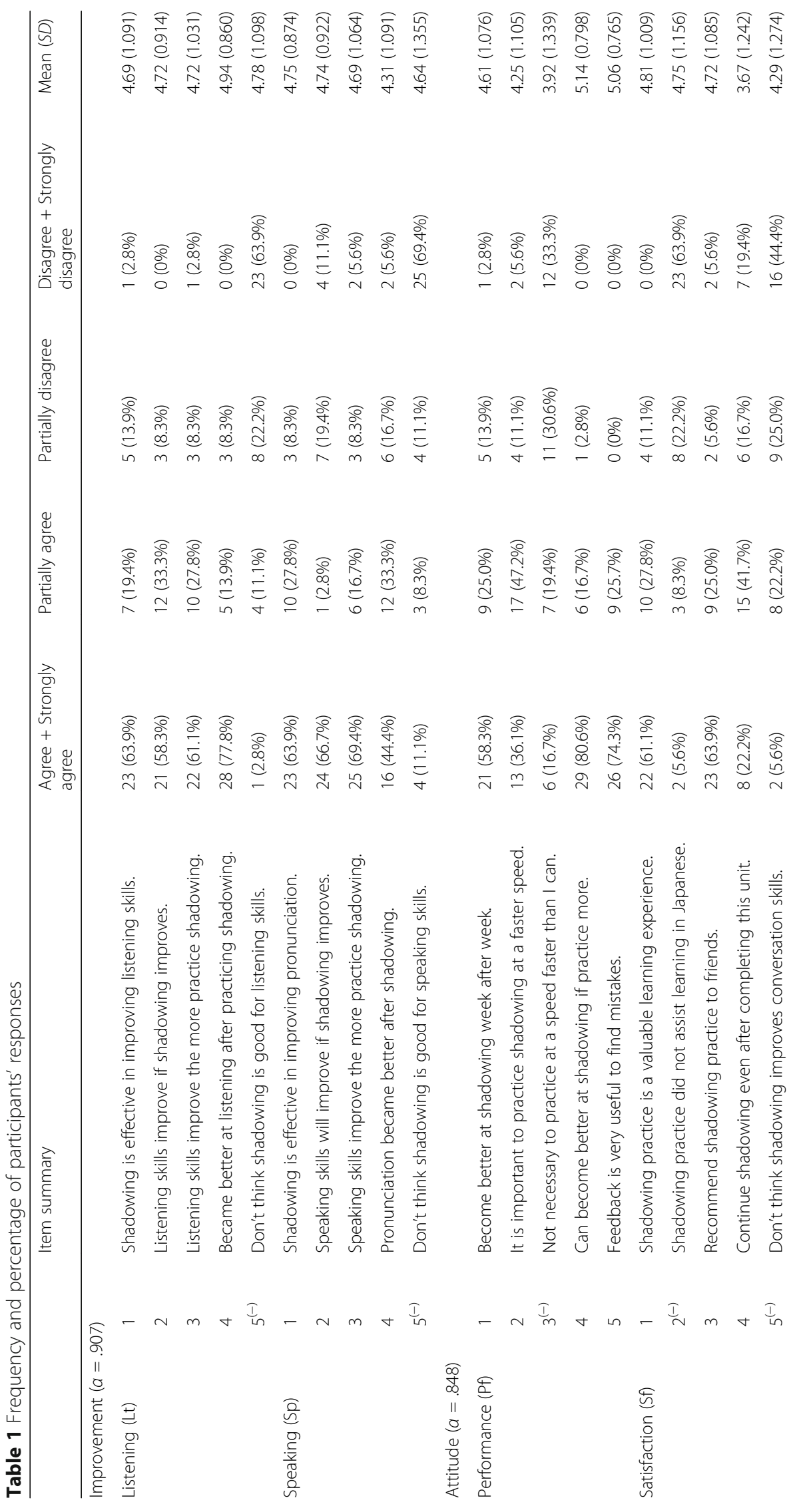




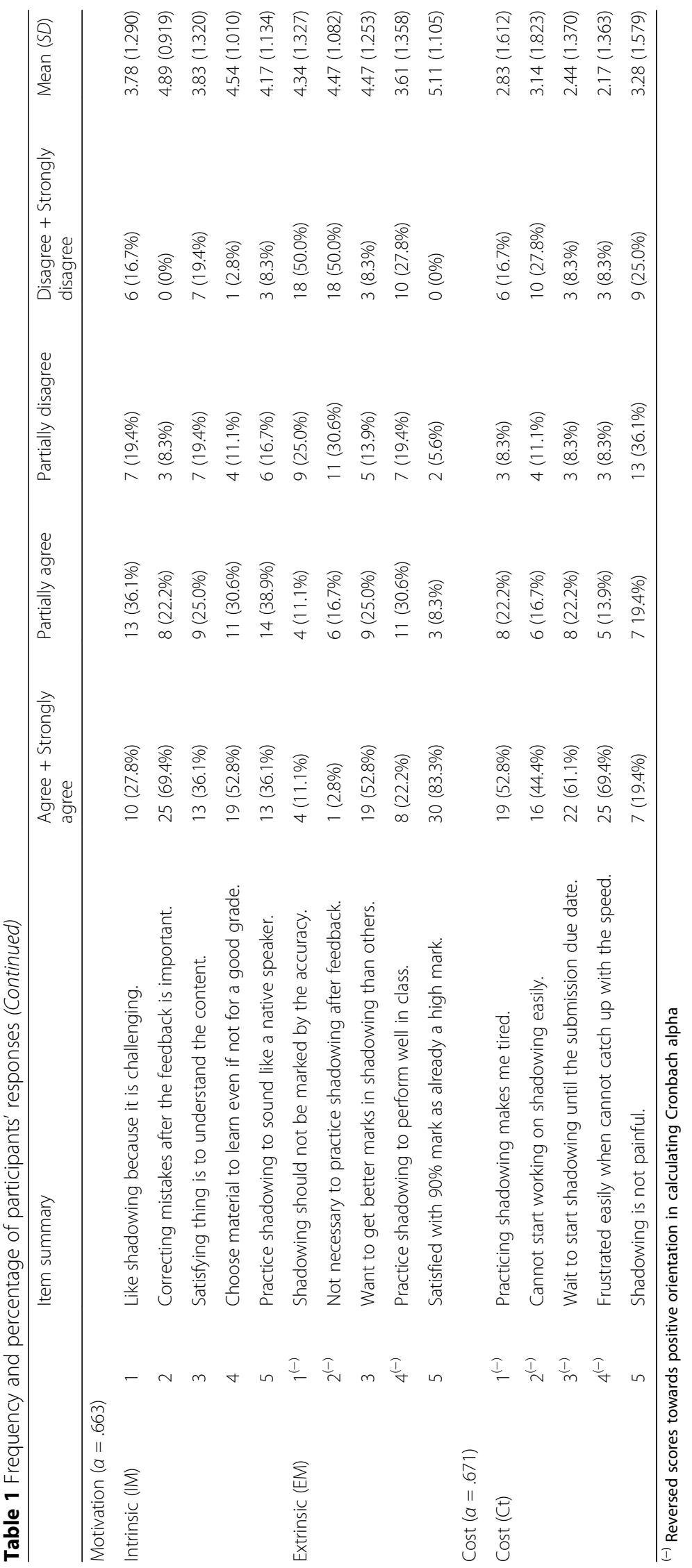




\section{Results and discussion}

\section{Participants' responses for questionnaire items}

Table 1 summarizes the frequency and percentage of responses for the 35 questionnaire items of the second part of the survey. The responses, 'Agree + Strongly Agree', and 'Disagree + Strongly Disagree', are put together for the purpose of the simple organization of the table; however, the actual scores of 6 scales were used, and negatively phrased items used reversed scores in order to align the positive consistency for statistical analyses. Cronbach alpha was calculated for internal consistent reliability for each category. The high consistency within the improvement $(\alpha=.907)$ and attitude $(\alpha=.848)$ is considered due to the question type being more simple and linear in either positive or negative expressions (e.g. 'I think shadowing is effective', 'I can become better at shadowing if I practice more'); whereas the motivation category $(\alpha=.663)$ and cost $(\alpha=.671)$, consisting of more complex expressions (e.g. 'If I can, I want to get better marks in shadowing than most of the other students', 'I wait to start shadowing until the submission due date'), resulted in lower Cronbach alpha value.

It is highly consistent that the majority of participants perceived improvement in listening and speaking in a favorable light, where well over $80 \%$ of the responses agree with the positive aspects of shadowing. A similar trend is seen in the category of attitude, that the responses are fairly positively oriented towards shadowing; and most salient of all, 100\% agreed that 'feedback is very useful' (Pf5); while 97\% think they can become better at shadowing with more practice (Pf4). However, 36\% think it is not necessary to practice shadowing at a speed faster than they can speak (Pf3). Although the majority (64\%) showed an intention to continue shadowing after this study (Sf4), the remaining population may likely not continue. In the category of motivation, the responses appear to fall into a diverse distribution: some are apparently positive, where 92\% agree that 'correcting mistakes after feedback is important' (IM2); and 81\% think it is necessary to practice after feedback (EM2), which is consistent with the above response in attitude (Pf5); and 94\% are 'satisfied with high mark' (EM5); others cannot be said to be either positive or negative. In the last category of cost, there is a definite trend in the responses towards negative orientation against shadowing, where participants tend to procrastinate in completing the shadowing assessment ( $\mathrm{Ct} 3$ and $\mathrm{Ct} 2$ ), and frustration about the fast speed (Ct4). Although the participants' responses in Table 1 reveal such complex attitudes towards shadowing, both positive and negative, as far as the research question (1) is concerned, it is reasonable to conclude that the great majority of participants perceive shadowing as effective for improving listening and speaking skills.

In order to identify underlying sources of attitudes towards shadowing, Principal Axis Factoring extraction was used to perform factor analysis on the second part of the survey questionnaires. Since the improvement in listening and speaking questionnaires contain similar expressions, three items out of five from each category (Lt3, Lt4, Lt5, Sp1, Sp2 and Sp5) were excluded for the analysis, based on the communality scores, in order to reduce redundancy. Initially, nine factors with eigenvalues greater than one were extracted. Judging from the degree of the eigenvalues, four factors were considered the most interpretable solution. A Promax rotation was performed since factors were expected to be correlated. Table 2 shows the four factors and named as 'positive speaking' (F1 = IM1, Pf1, Sf4, Sf3, Sp4, Sp3, EM1, Pf2 and IM4), 'accurate listening' 
Table 2 Results of factor analysis with promax rotation

\begin{tabular}{|c|c|c|c|c|c|}
\hline Item & $\mathrm{F} 1$ & $F 2$ & F3 & F4 & Communality \\
\hline \multicolumn{6}{|c|}{ F1 (Eigenvalue $=9.14(31.5 \%), a=.879)$} \\
\hline IM1 & 0.904 & -0.150 & -0.042 & 0.015 & 0.705 \\
\hline Pf4 & 0.850 & 0.045 & 0.172 & -0.400 & 0.687 \\
\hline Pf1 & 0.670 & 0.001 & -0.147 & 0.108 & 0.502 \\
\hline $\mathrm{Sf} 4$ & 0.669 & 0.039 & 0.010 & 0.031 & 0.498 \\
\hline Sf3 & 0.660 & 0.172 & 0.068 & 0.032 & 0.624 \\
\hline Sp4 & 0.642 & 0.114 & -0.281 & 0.079 & 0.548 \\
\hline $\mathrm{Ct} 2^{(-)}$ & 0.634 & -0.308 & 0.360 & 0.278 & 0.724 \\
\hline Sp3 & 0.589 & 0.191 & -0.083 & 0.011 & 0.485 \\
\hline $\mathrm{Ct} 5$ & 0.555 & -0.098 & 0.346 & 0.158 & 0.565 \\
\hline $\mathrm{EM}^{(-)}$ & 0.503 & -0.057 & 0.158 & 0.024 & 0.296 \\
\hline Pf2 & 0.407 & -0.005 & -0.231 & 0.192 & 0.272 \\
\hline IM4 & 0.329 & 0.115 & 0.084 & -0.168 & 0.144 \\
\hline \multicolumn{6}{|c|}{ F2 (Eigenvalue $=3.04(10.5 \%), a=.858$ ) } \\
\hline $\mathrm{EM}^{(-)}$ & -0.170 & 0.740 & 0.207 & -0.024 & 0.493 \\
\hline $\mathrm{Sf} 2^{(-)}$ & 0.360 & 0.651 & 0.018 & -0.098 & 0.730 \\
\hline $\mathrm{Sf5}^{(-)}$ & 0.468 & 0.605 & -0.034 & -0.213 & 0.743 \\
\hline Lt2 & 0.213 & 0.598 & -0.134 & 0.272 & 0.732 \\
\hline IM3 & -0.221 & 0.585 & 0.496 & 0.256 & 0.635 \\
\hline Lt1 & 0.445 & 0.576 & -0.177 & -0.054 & 0.734 \\
\hline \multicolumn{6}{|c|}{ F3 (Eigenvalue $=2.18(7.51 \%), a=.694)$} \\
\hline EM3 & -0.183 & 0.119 & 0.754 & -0.118 & 0.550 \\
\hline IM5 & -0.089 & 0.252 & 0.615 & -0.002 & 0.424 \\
\hline $\mathrm{Pf} 3^{(-)}$ & 0.204 & 0.322 & 0.500 & -0.202 & 0.461 \\
\hline $\mathrm{Ct}^{(-)}$ & 0.140 & 0.189 & 0.497 & 0.217 & 0.493 \\
\hline $\mathrm{EM} 4^{(-)}$ & 0.130 & -0.168 & 0.461 & -0.057 & 0.247 \\
\hline Ct 4 & 0.240 & -0.319 & 0.365 & 0.121 & 0.269 \\
\hline \multicolumn{6}{|c|}{ F4 (Eigenvalue $=1.93(6.65 \%), a=.650)$} \\
\hline EM5 & -0.111 & -0.125 & -0.063 & 0.667 & 0.371 \\
\hline Sf1 & 0.218 & 0.291 & -0.204 & 0.562 & 0.695 \\
\hline Pf5 & 0.089 & -0.031 & 0.062 & 0.554 & 0.362 \\
\hline IM2 & -0.088 & 0.226 & 0.252 & 0.469 & 0.375 \\
\hline
\end{tabular}

${ }^{(-)}$Reversed scores towards positive orientation

(F2 = EM2 and Lt2), 'good appearance' (F3 = EM3, IM5, Ct1 and EM4), and 'feedback for marks' (F4 = EM5, Sf1, Pf5 and IM2), based on the items loaded on each factor. Nine items (Pf4, Ct2, Ct5, Sf2, Sf5, IM3, Lt1, Pf3 and Ct4) were not referred to in the naming process, because they were overlapping more than two factors at above 0.3 factor loading scores.

The first factor was named 'positive speaking', because it includes favorable attitudes toward shadowing, such as intention to continue shadowing, recommend to friends, like because challenging; and includes speaking skills such as pronunciation and fast speed. The second factor was named 'accurate listening', because it consists of the items referring to correcting mistakes and improving listening. The third factor was named 
'good appearance', since it includes items expressing comparison to other students, inclass performance, and sounding like a native speaker. The fourth factor was named 'feedback for marks', as it contains items regarding feedback usefulness and shadowing marks. It is interesting to see how those factors are extracted in certain trends, such as speaking skill with positive attitude (F1) and listening skill with accuracy (F2), which suggests participants tend to perceive speaking skills with more optimistic view than listening skills. In other words, speech output itself is vital in the communicative language teaching context, because the active participation in the communication is the primary target. In such a context, willingness to speak is often valued more than the accurate use of the L2. However, when it comes to listening skills, accuracy is of crucial importance in order to gather accurate information. As for the third factor (F3), it is understandable that, in-class competition and desire to maintain social appearances, or even a desire to impress other peers by native-like L2 speech, naturally occur in group psychology. Finally, the fourth factor (F4) indicates that shadowing feedback is crucial for finding mistakes and getting higher marks. As shown in Table 3, there is a correlation between F1 (positive speaking) and F2 (accurate listening) at $p<0.01$ level; and between F1 (positive speaking) and F4 (feedback for marks) at $p<0.05$ level.

There is a tendency that the 'positive speaking' and 'accurate listening' factors are highly correlated, with statistical significance, because shadowing targets these very oral/aural skills. Likewise, 'positive speaking' is significantly correlated to 'feedback for marks', which indicates participants' perception of the usefulness of feedback in improving speaking skills. However, 'positive speaking' is not correlated to 'accurate listening', which appears puzzling, because feedback is indispensable for accuracy building. In one explanation, however, this is largely due to the marking method in the present study: that is, the feedback marks are solely based on the accuracy of shadowing (speech production) but not on comprehension of the content (listening). Therefore, it is reasonable to assume that participants develop linkage between feedback and speaking skills, but not listening skills. The third factor, 'good appearance', has no significant correlation to any of the other factors. This is considered to be due to the administration of the shadowing practice as a homework assessment in this study. Speaking activity in the individual's private space, with the freedom of choosing the practice time, undoubtedly helps reduce pressure of in-class competition and/or anxiety of speech presentation.

In order to investigate Research Question 2, participants were divided into two groups, of above and below the median score (50.4), based on their average shadowing performance scores; and they were labelled High Performance (HP, $n=18)$ and Low Performance (LP, $n=18$ ), respectively. In measuring the intention to continue

Table 3 Correlation between the four factors

\begin{tabular}{lllll}
\hline & $F 1$ & $F 2$ & $F 3$ & $F$ \\
\hline F1 (positive speaking) & 1.000 & & & \\
F2 (accurate listening) & $0.544^{* *}$ & 1.000 & 1.000 & \\
F3 (good appearance) & 0.230 & 0.069 & 0.150 & 1.000 \\
\hline F4 (feedback for marks) & $0.384^{*}$ & 0.159 & \\
\hline
\end{tabular}

${ }^{* *}$. Correlation is significant at $p<.01$ level (2-tailed)

${ }^{*}$. Correlation is significant at $p<.05$ level ( 2 -tailed) 
shadowing, the questionnaire item, 'I will continue practicing shadowing even after completing this unit' (Sf4), was set as the dependent variable. Pearson correlation was calculated with other items as the independent variable. The ten most common items are presented in Table 4. In the HP group, five items (IM1: 'like shadowing because challenging, EM1: 'should be marked by submission but not by accuracy', Lt1: 'effective in improving listening skills', Sf3: 'recommend shadowing to friends', and Sf2: 'did not assist language learning') were significantly correlated at $p<.01$ level; and another five items (IM3: 'satisfying thing is to understand content', Pf1: 'become better at shadowing weekly', Pf4: 'become better at shadowing if practice', Sp5: 'shadowing is not good for speaking skills', and Ct2: 'cannot start shadowing easily') were at $p<.05$ level. On the other hand, the LP group has fewer items with statistical significance: three items (Pf1: 'become better at shadowing weekly', Sf1: 'shadowing is valuable learning experience', and Sp1: 'effective in improving speaking skills') are correlated at $p<.01$ level; and four items (IM4: 'choose materials to learn from,' IM1: 'like shadowing because challenging', Pf2: 'important to practice at fast speed' and Sp4: 'pronunciation became better') are at $p<.05$ level. There are only two items (IM1 and Pf1) that are common to HP and LP with statistical significance.

The most salient trend in the HP group in relation to intention to continue shadowing is the challenging (IM1) characteristic of shadowing. The model audio of native speech is certainly challenging for L2 learners; however, the accuracy-based assessment (EM1) enables them to project the discrepancy between the present and ideal selves, especially for those who are able to perform shadowing better than others, and see the discrepancy as minimal, and therefore, manageable. This realistic ideal self helps in setting up the concrete path towards the goal. Such successful experiences would undoubtedly encourage motivation to continue shadowing; or applying Ryan and Deci's (2000) self-determination theory, this falls within integrated regulation (a form of extrinsic motivation that is closest to intrinsic motivation: e.g. willing to do because it is good for improvement). This positive intention also reflects the willingness to recommend shadowing to other L2 learners (Sf3). Because of the high shadowing performance in this group, it is natural that participants perceive shadowing as effective in

Table 4 Top ten correlation values based on intention to continue shadowing

\begin{tabular}{|c|c|c|c|c|c|c|}
\hline & \multicolumn{3}{|c|}{ High performance $(n=18)$} & \multicolumn{3}{|c|}{ Low performance $(n=18)$} \\
\hline & Item & Correlation & Mean $(S D)$ & Item & Correlation & Mean (SD) \\
\hline 1 & $\mathrm{IM} 1$ & $0.820^{* *}$ & $4.17(1.295)$ & Pf1 & $0.730^{* *}$ & $4.39(1.195)$ \\
\hline 2 & $\mathrm{EM} 1^{(-)}$ & $0.778^{* *}$ & $4.61(1.092)$ & Sf1 & $0.668^{* *}$ & $4.56(1.097)$ \\
\hline 3 & Lt1 & $0.654^{* *}$ & $4.67(0.840)$ & Sp1 & $0.633^{* *}$ & $4.67(0.907)$ \\
\hline 4 & $\mathrm{Sf3}$ & $0.641^{* *}$ & $4.83(0.985)$ & IM4 & $0.570^{*}$ & $4.72(1.127)$ \\
\hline 5 & $\mathrm{Sf} 2^{(-)}$ & $0.606^{* *}$ & $5.00(1.029)$ & $\mathrm{IM} 1$ & $0.565^{*}$ & $3.39(1.195)$ \\
\hline 6 & IM3 & $0.587^{*}$ & $3.89(1.323)$ & $\mathrm{Pf} 2$ & $0.562^{*}$ & $4.06(0.998)$ \\
\hline 7 & Pf1 & $0.587^{*}$ & $4.83(0.924)$ & Sp4 & $0.471^{*}$ & $3.94(1.110)$ \\
\hline 8 & Pf4 & $0.565^{*}$ & $5.11(0.832)$ & Pf4 & 0.449 & $5.17(0.786)$ \\
\hline 9 & $\mathrm{Sp} 5^{(-)}$ & $0.548^{*}$ & $5.06(0.998)$ & $\mathrm{Sf5} 5^{(-)}$ & 0.445 & $4.22(1.555)$ \\
\hline 10 & $\mathrm{Ct} 2^{(-)}$ & $0.535^{*}$ & $3.11(1.711)$ & Sp3 & 0.443 & $4.72(1.227)$ \\
\hline
\end{tabular}

*. Correlation is significant at $p<.01$ level (2-tailed)

${ }^{*}$. Correlation is significant at $p<.05$ level (2-tailed)

${ }^{(-)}$Reversed scores towards positive orientation 
listening skills (Lt1), and are interested in the content of the script (IM3). Comprehension of the content requires higher level of linguistic processing, which is built upon bottom-up language processing, starting from the minimum element of the speech, such as sound, morpheme, word, sentence, and so on. Shadowing is fundamentally targeted to automatize this bottom-up processing so that the brain can focus its limited resources on higher language processing in order to comprehend the content (Kadota 2007).

In contrast, the LP group follows a different trend from its counterpart: in a nutshell, with physical rather than mental aspects, such as perceived improvement in shadowing performance (Pf1, Pf2 and Pf4) and pronunciation/speaking skills (Sp1, Sp4 and Sp3), among other positive aspects of shadowing such as valuable experience (Sf1) and challenging (IM1). This clearly indicates that the intention to continue shadowing among participants with lower shadowing skills is based on bottom-up processing; or in Ryan and Deci's (2000) term, those extrinsically motivated in identification (the second closest to intrinsic motivation: e.g. willing to do because it is relevant). The equation, that improvement in shadowing performance equals improvement in pronunciation, means improvement in bottom-up processing to aim at higher level of the language processing ladder. It is understandable that they tend to focus on the discrepancy between the present and ideal self while the gap is still large and noticeable. It is the feedback that motivates them to continue shadowing, by providing visible steps to depart from their present selves. In sum, the results shown in Table 4 reveal attitudinal differences depending on the level of mastery of shadowing performance: that is, capable participants are likely to continue shadowing if they find it challenging, effective to their L2 learning, and if feedback is provided to show how much and where they need to improve. On the other hand, less capable participants would continue shadowing if they can improve their basic language skills such as pronunciation and sound recognition.

Besides the correlation value, the mean score of each item must also be taken into consideration, in order to measure the relative positivity with regard to the intention to continue shadowing (Research Question 3). Firstly, a scatter diagram was generated based on the correlation value (Y-axis) and the item mean scores (X-axis). Secondly, the mean of the correlation values and the item scores of the 34 questionnaire items in HP and LP groups were calculated (HP: item $M=4.27$, correlation $M=0.367$; LP: item $M=4.10$, correlation $M=0.303$ ), and placed as the origin of the coordinate axes (dotted cross, see Fig. 3). Thirdly, items in the area above mean correlation value and below mean item score were identified (encircled area). These are the variables considered extremely important because of the high correlation to the intention item (Sf4) with below average positivity, which poses room for improvement in encouraging the intention to continue shadowing in the future.

Common to both HP and LP groups, Ct2 ('I cannot start working on shadowing easily') and IM1 ('I like shadowing because it is challenging') were identified in the encircled area. HP included IM3 ('the most satisfying thing is to understand the content'), while Pf2 ('I became better at shadowing') and Sp4 ('My pronunciation became better') were found only in LP group. In order to investigate the relationship between these identified variables, correlation was calculated (see Table 5), and significant correlation was found between Ct2 and IM1 $(r=0.522, p<.05)$ as well as IM1 


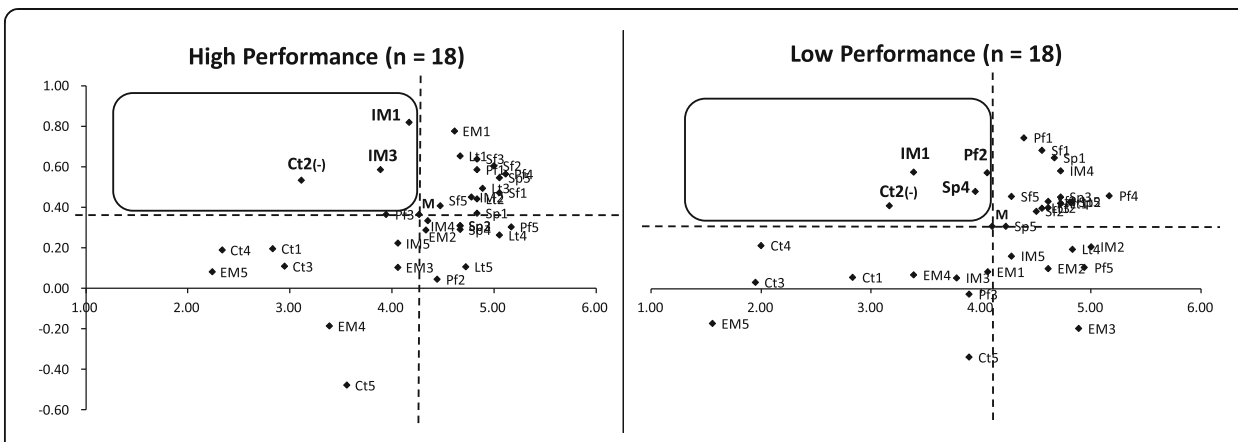

Fig. 3 Diagram of Mean of Correlation and Item Scores Based on Intention to Continue Shadowing

and IM3 $(r=0.492, p<.05)$ for HP group; and Ct2 and Sp4 $(r=0.487, p<.05)$, IM1 and Pf2 $(r=0.671, p<.01)$ and IM1 and Sp4 $(r=0.638, p<.01)$ for LP group.

In the HP group, the challenging characteristic of shadowing (IM1) is the common variable in correlation to the sense of cost $(\mathrm{Ct} 2)$ and satisfaction in understanding the content (IM3). This can create a linear relationship between the variables where significant correlation values function as juncture, that is, IM3 - IM1 - Ct2 line. The line is not directional, because the Pearson correlation does not assume the cause and effect relationship; however, considering procrastination (Ct2) is much like the effect than cause, this line would most likely be interpreted as: content comprehension (IM3) is challenging (IM1), so cannot start working on shadowing easily (Ct2). Therefore, it is suggested that content comprehension of shadowing materials is the key factor in order to improve the item scores of these variables. In other words, it is crucial to take content into consideration in order to encourage participants in the HP group to continue shadowing in the future.

In contrast, there is a different pattern in the LP group: challenging (IM1) and pronunciation (SP4) are the common variables in significant correlation to becoming better at shadowing (Pf2) and procrastination (Ct2), respectively. Applying the same method of correlation juncture above, Pf2 - IM1 - Sp4 - Ct2 line is created. This can be interpreted as: improving shadowing every week (Pf2) is challenging (IM1) as much

Table 5 Correlation between the variables encircled in Fig. 3

\begin{tabular}{|c|c|c|c|c|}
\hline & $\mathrm{Ct} 2^{(-)}$ & IM1 & $\mathrm{IM} 3$ & \\
\hline $\mathrm{Ct} 2^{(-)}$ & 1.000 & & & \\
\hline IM1 & $0.522^{*}$ & 1.000 & & \\
\hline IM3 & 0.317 & $0.492^{*}$ & 1.000 & \\
\hline \multicolumn{5}{|c|}{ Low performance } \\
\hline & $\mathrm{Ct} 2^{(-)}$ & $\mathrm{IM} 1$ & Pf2 & Sp4 \\
\hline $\mathrm{Ct} 2^{(-)}$ & 1.000 & & & \\
\hline IM1 & 0.394 & 1.000 & & \\
\hline $\mathrm{Pf} 2$ & 0.412 & $0.671^{* *}$ & 1.000 & \\
\hline Sp4 & $0.487^{*}$ & $0.638^{* *}$ & 0.162 & 1.000 \\
\hline
\end{tabular}

${ }_{*}^{*}$. Correlation is significant at $p<.01$ level (2-tailed)

*. Correlation is significant at $p<.05$ level (2-tailed)

${ }^{(-)}$Reversed scores towards positive orientation 
as improving pronunciation (Sp4), therefore cannot start working on shadowing easily (Ct2). Considering that shadowing tends to be regarded with the emphasis on bottomup processing by the participants in the LP group, as discussed in the above section, it is suggested that accurate pronunciation is the key factor in order to improve the item scores of these variables. The result, accordingly, implies that difficulty level of shadowing materials and audio speed need to match the participants' level so that they can maintain high accuracy in their shadowing performance.

\section{Participants' responses for open-ended questions}

In response to the open-ended questions of the third part of the survey, 'What do you think are the positive aspect(s) of shadowing practice?', and 'What do you think are the negative aspect(s) of shadowing practice?' (Research Question 4), most participants responded with the following comments: positive aspects: $97 \%, n=34$; negative aspects: $89 \%, n=31$. Table 6 summarizes the frequency of the key comments in the HP and LP groups, sorted by the total frequency in each question. There were almost twice as many comments in the positive aspects (total: $n=72$ ) as the negative aspects (total: $n=40$ ), where there were equal number in both groups for the positive aspects (HP: $n=36$, LP: $n=36$ ); and more comments from the LP group for the negative aspects $(n=22)$ than for those from the HP group $(n=18)$.

In terms of the group difference for the positive aspects, the LP group made a predominant number of comments on improvements in speaking $(n=11)$ and listening ( $n=11)$, compared to the HP group $(n=6, n=4$, respectively). This is assumed to be because the degree of the improvement perceived by the participants in the LP group was larger than those in the HP group. This echoes Tamai's (2002) study results on the effect of shadowing on listening skills among Japanese EFL learners, that shadowing was more effective for students with lower English proficiency than for those with higher proficiency, which is considered to be due to there being more room for improvement. As with the case in the present study, participants with lower shadowing

Table 6 Frequency of participants' responses in open questions

\begin{tabular}{llllll}
\hline Positive aspects & \multicolumn{2}{l}{ High performance } & Low performance & Total \\
\hline Improve speaking & 6 & $(16,20,25,28,30,34)$ & 11 & $(3,4,6,13,15,18,24,29,33,35,36)$ & 17 \\
Improve listening & 4 & $(16,25,30,31)$ & 11 & $(3,4,6,13,15,18,21,24,29,35,36)$ & 15 \\
Improve pronunciation & 7 & $(1,10,19,20,23,25,27)$ & 5 & $(3,7,26,33,35)$ & 12 \\
Native-like speech & 7 & $(5,10,12,16,17,19,27)$ & 3 & $(3,7,22)$ & 10 \\
Fast speed & 6 & $(2,10,16,27,28,32)$ & 3 & $(3,9,22)$ & 9 \\
Understanding & 4 & $(10,17,23,31)$ & 2 & $(33,35)$ & 6 \\
Fun/interesting & 2 & $(2,10)$ & 1 & $(36)$ & 3 \\
Total & 36 & & 36 & & 72 \\
Negative aspects & & & & & 10 \\
Speed too fast & 6 & $(5,16,20,23,25,30)$ & 12 & $(4,7,9,13,15,18,22,24,26,33,35,36)$ & 18 \\
Frustrated/stressed & 5 & $(10,20,25,30,31)$ & 5 & $(3,13,15,21,35)$ & 9 \\
Difficult to understand & 4 & $(12,14,28,31)$ & 5 & $(3,4,6,8,13)$ & 3 \\
Time consuming & 3 & $(5,10,27)$ & 0 & & 40 \\
Total & 18 & & 22 & & \\
\hline
\end{tabular}

Participant ID number is shown in (brackets) 
proficiency would have more opportunity to realize a degree of the improvement before and after the practice than those with high proficiency who can perform shadowing well already from the beginning. It is interesting to find that more HP participants commented on the improvement in pronunciation $(n=7)$ and native-like speech $(n=7)$ than did LP participants $(n=5, n=3$, respectively), because these are specific aspects in the domain of speaking skills. This suggests that proficient participants are more aware of focused features of speaking skills than are less proficient participants, the latter who tend to perceive speaking skills in general terms. In fact, putting these three aspects together (speaking, pronunciation, and native-like speech), HP and LP sum up in almost equal numbers $(\mathrm{HP}=20, \mathrm{LP}=19)$.

It is also understandable that more HP participants commented on sophisticated aspects of shadowing as positive, such as fast speed of the model audio $(n=6)$ and understanding the content of the materials $(n=4)$ than did LP participants $(n=3$, $n=2$, respectively). This is assumed to be because proficient participants can utilize their brain resources besides bottom-up processing for higher language processing to comprehend the content, which can also help accelerate the processing speed once succeeding in automatizing the lower language processing.

As for the negative aspects, the most salient difference between the groups is the number of the comments against the shadowing speed by the LP participants $(n=12)$, which is twice as many as HP participants $(n=6)$. This is a convincing result, because the weekly speed progression of the model audio inevitably increases the difficulty level, especially for those with less proficient participants. However, it is the pedagogical design to adopt this gradual speed progression in order to offer adequate challenge for the L2 learners to make steady progress. Learners then must make effort in order to achieve this goal; which effort may be recognized in the form of challenge or cost, depending on how they perceive the process. In fact, an equal number of participants in the HP group $(n=6)$, and even a small number in the LP group $(n=3)$, perceived the speed progression as positive. It is, however, something that must be considered in future implementation of shadowing practice, with regard to how to adjust the speed progression.

Another outstanding difference between the groups is the comment regarding the time-consuming aspect of shadowing by HP participants $(n=3)$. This indicates the causal relationship between the amount of time and the shadowing proficiency of these participants: that they maintain high shadowing performance because they spend time. However, the fact that they commented on this time-consuming aspect as negative is either because they simply require more time than other peers, or because feel that they are making no or little progress while practicing shadowing. It is probable that it is the latter scenario in this case: capable students tend to focus on the deduction from $100 \%$, and develop more anxiety from the discrepancy. So-called perfectionist participants may have seen their shadowing performance more from a fear of failure than from a feeling of success, because $95 \%$ accuracy is still a 5\% deduction from their ideal result (Gregersen and Horwitz 2002). However, as is suggested in the shadowing improvement to hit the ceiling point after four or five times (Shiki et al. 2010), it is of crucial importance to indicate the goal at the peak of the progress: in other words, practitioners are strongly recommended to remind students to practice shadowing six times but not more than eight times, because little or no progress with greater effort would result in demotivation. 
Similar to the comments on the speed of shadowing, understanding of the content also plays an important role in shadowing, since this appears in both positive and negative aspects. The same number of participants made comments on this aspect in the HP group (positive: $n=4$, negative: $n=4$ ) and more negative in the LP group (positive: $n=2$, negative: $n=5$ ). The increase in the number of comments in the LP group in this aspect is considered to be because there were more participants who were not capable of utilising their brain resources enough to comprehend the content, hence, shadowing practice without understanding the content is perceived as negative. The fact that there were an equal number of comments expressing frustration/stress against shadowing in HP group $(n=5)$ and LP group $(n=5)$ is a reflection of the aforementioned negative aspects such as speed, being time consuming, and having content without comprehension, among other possible aspects.

As for the third open-ended question, 'How do you think shadowing practice can be improved?', most participants responded with comments $(89 \%, n=31)$ with various suggestions. The most common comments $(n=6)$ were regarding the frequency of shadowing, to increase the total number of shadowing weeks (HP-2), or re-submission after the feedback to observe improvement on the same material (LP-7, LP-8, LP-33); or more shadowing opportunities to reduce the pressure per submission (HP-16, LP35). These suggestions represent a positive attitude towards shadowing, in that participants are more motivated to practice shadowing than the current shadowing frequency. However, the challenge is the actual practicality of the shadowing administration of feedback marking system by the teaching staff, with regard to the required workload for marking. The most feasible adjustment is to shift the marking system onto the learners' side as a self-study by the student him/herself; but this can occur only after sufficient scaffolding has been provided so that students become able to self-assess and observe the accurate discrepancy between the model audio and their shadowing performance.

Next to the shadowing frequency, four comments were made regarding the content of the shadowing materials. Two participants (LP-26, HP-28) wished to have English translations along with the script, in order to assist comprehension; and the others (HP-5, HP-25) suggested that shadowing content be more interesting. The realization of the former suggestion, an English translation, is fairly simple and possible to provide. However, it may be even more interesting to have learners translate themselves before releasing the translation as an answer, for more effective learning of shadowing materials in enhancing the comprehension of the content. This is closely related to the latter suggestion, to use more interesting content for shadowing to attract learners' attention to the meaning of the materials. In this viewpoint, authentic materials can be used for shadowing such as media clips from movies, TV dramas, and anime, which would certainly add other prosodic features to shadowing performativity besides accuracy. In addition, using drama performance in the language curriculum would encourage students to appropriately consider the context of language usage and to apply what they learn in the activity to real-life situations (Hewgill et al. 2004). However, the selection criteria of shadowing materials must be based on the objectives and learning outcomes of the curriculum. As an introduction of shadowing for first timers, in order to develop a solid foundation of the shadowing technique, monologic script in a steadily paced model audio is considered ideal to meet the accuracy-based objective. 


\section{Conclusion}

The results of this study indicate that the majority of participants perceive shadowing as effective for both listening and speaking skills. Responses in the open-ended questions also support this point. In addition, all the participants agree on the usefulness of feedback, and believe that more shadowing practice will improve speaking/listening skills. However, individual differences were found in how they favor the shadowing materials at fast speed, especially at a speed that their comprehension cannot process appropriately. This implies the following possible improvement in shadowing administration in class. In order to encourage content shadowing, it is important to establish a checking system that allows participants to review the degree of comprehension of the content. The method would vary depending on the level of engagement required from the participants, from as simple a task as a small quiz on the content (e.g. multiple choice, fill-in-the-blank, open-end questions, etc.) to translation of the entire script. As for the speed progression, it is the principal reason for the negative attitudes towards shadowing in this study, because of the speed being too fast for certain participants to keep up with. However, it is also true that others perceive the speed to be adequate and positively challenging. In solving this dilemma, it is suggested to create two or even three versions at different speeds to meet the levels of participants' shadowing proficiency. In doing so, participants' performance must be closely monitored, and the most appropriate speed could be assigned: for instance, the feedback could include the instruction as to which suggested version of the shadowing material to download for the following week; or it could be self-assigned: students choose depending on level of challenge/frustration.

It is a limitation of this study that the number of participants was small, especially for factor analysis, to generalize the results. This is because the study was conducted on an advanced-level language unit, where the population is usually smaller than in lower levels. Therefore, more research based on the findings of this study is recommended at different levels, such as intermediate and/or introductory levels, where a much larger population is usually expected.

\section{Additional file}

Additional file 1: Shadowing Survey. (DOCX 14 kb)

\section{Authors' contributions}

HS developed the design of the study, carried out the teaching, performed the statistical analysis, and drafted the manuscript. CS participated in the design of the study and helped to revise the manuscript critically for important intellectual content. All authors read and approved the final manuscript.

Competing interests

The authors declare that they have no competing interests.

\section{Publisher's Note}

Springer Nature remains neutral with regard to jurisdictional claims in published maps and institutional affiliations.

Received: 6 July 2017 Accepted: 19 September 2017

Published online: 02 October 2017

\section{References}

Aida, Y. (1994). Examination of Horwitz, Horwitz, and Cope's Construct of Foreign Language Axiety: The Case of Sutdents of Japanese. The Modern Lanquage Journal, 78(2), 155-168. doi:10.1111/j.1540-4781.1994.tb02026.x. Baddeley, A. D. (1992). Working Memory. Science, 255(5044), 556-559. 
Deci, E., Vallerand, R., Pelletier, L., \& Ryan, R. (1991). Motivation and Education: The Self-Determination Perspective. Educational Psychologist, $26(3$ \& 4), 325-346. doi:10.1080/00461520.1991.9653137.

Dörnyei, Z. (2002). The Motivational Basis of Language Learning Tasks. In P. Robinson (Ed.), Individual Differences in Second Language Acquisition (pp. 138-158). Amsterdam: John Benjamins.

Dörnyei, Z. (2009). The L2 Motivational Self System. In Z. Dornyei \& E. Ushioda (Eds.), Motivation, language identity and the L2 self (pp. 9-42). Bristol: Multilingual.

Gardner, R. C. (1985). Social Psychology and Second Language Learning: The Role of Attitudes and Motivation. London: Edward Arnold.

Gardner, R. C. (2001). Integrative Motivation and Second Language Acquisition. In Z. Dörnyei \& R. Schmidt (Eds.), Motivation and Second Language Acquisition. Honolulu: University of Hawaii Press.

Gregersen, T., \& Horwitz, E. (2002). Language Learning and Perfectionism: Anxious and Non-Anxious Language Learner's Reactions to Their Own Oral Performance. The Modern Language Journal, 86(4), 562-570.

Hamada, Y. (2011a). Improvement of Listening Comprehension Skills through Shadowing with Difficult Materials. The Journal of Asia TEFL, 8(1), 139-162.

Hamada, Y. (2011 b). Psychological Aspects of Shadowing Training. The Japan Association for Developmental Education $6(2), 60-71$.

Hamada, Y. (2012). An Effective Way to Improve Listening Skills through Shadowing. The Language Teacher, 36(1), 3-10.

Hamada, Y. (2015). Uncovering Shadowing as an EFL Teaching Technique for Listening: Learners' perceptions, selfconfidence, and motivation. Akita University Annual Research Report on General Education, 9(22), 9-22.

Hamada, Y. (2016). Shadowing: Who Benefits and How? Uncovering a Booming EFL Teaching Technique for Listening Comprehension. Language Teaching Research, 20(1), 35-52. doi:10.1177/1362168815597504.

Hewgill, D., Noro, H., \& Poulton, C. (2004). Exploring Drama and Theatre in Teaching Japanese: Hirata Oriza's Play, Tkyo Notes, in an Advanced Japanese Conversation Course. Sekai no Nihongo Kyoiku, 19, 227-252.

Horwitz, E., Horwitz, M., \& Cope, J. (1986). Foreign Language Classroom Anxiety. The Modern Language Journal, 70(2), 125-132. doi:10.1111/j.1540-4781.1986.tb05256.x.

Kadota, S. (2007). Shadowing to Ondoku no Kagaku (Shadowing and the Science of Oral Reading). Tokyo: CosmoPier Publishing Company.

Kadota, S. (2012). Shadowing, Ondoku to Eigo shutoku no Kagaku (The Science of Shadowing, Oral Reading and English Aquisition). Tokyo: CosmoPier Publishing Company.

Kadota, S., \& Tamai, K. (2004). Ketteiban, Eigo Shadowing (The Definitive Edition English Shadowing). Tokyo: CosmoPier Publishing Company.

Kurata, K. (2007). A Fundamental Study on the Cognitive Mechanism of Shadowing in Japanese - From the view point of oral reproduction, memory span and sentence structure. Bulletin of the Graduate School of Education, Hiroshima University, 56(2), 259-265.

Kyo, H. (2012). Nihongo Gakushu ni Mirareru Shadowing no Kouka. Meikai Nihongo, 17, 103-111.

Lambert, S. (1992). Shadowing. Meta, 37(2), 263-273.

Maclntyre, P. D., \& Gardner, R. C. (1991). Methods and Results in the Study of Anxiety and Language Learning: A Review of the Literature. Language Learning, 41(1), 85-117.

Markee, N. (1992). The Diffusion of innovations in language teaching. Annual Review of Applied Linguistics, 13, 229-243.

Mochizuki, M. (2006). On the Application of Shadowing Method to Japanese Language Education : With Special Reference to Relevance of Learners' Japanese Competence to Their Self-Assessment of the Effects of Shadowing. Kansai University Audio-Visual Education, 29, 37-53.

Pintrich, P. R., Smith, D. A. F., Garcia, T., \& McKeachie, W. J. (1991). A Manual for the Use of the Motivated Strategies for Learning Questionnaire (MSLQ). Michigan: The Univercity of Michigan.

Ryan, R. M., \& Deci, E. L. (2000). Intrinsic and Extrinsic Motivations: Classic Definitions and New Directions. Contemporary Educational Psychology, 25, 54-67. doi:10.1006/ceps.1999.1020.

Saito, Y., Nagasawa, Y., \& Ishikawa, S. (2011). Effective Instruction of Shadowing Using a Movie. JALT Conference Proceedings, JALT, 2010, 139-148.

Sasaki, M. (2007). The 150-year history of English language assessment in Japanese education. Language Teaching, 25(1), 63-83.

Shiki, O., Mori, Y., Kadota, S., \& Yoshida, S. (2010). Exploring Differences Between Shadowing and Repeating Practices: An Analysis of Reproduction Rate and Types of Reproduced Words. Japan Society of English Language Education, 21, 81-90.

Spiller, E., Daro, V., BFabbro, F., \& Bosatra, A. (1990). Audio-Phonological and Neuropsychological Aspects of Simultaneous Interpretation: Role of Auditory Shadowing. Scandinavian Audiology, 19, 81-87.

Tamai, K. (1992). "Follow-up" no Choryoku Kojo ni Oyobosu Koka Oyobi "Follow-up" Noryoku to Chokairyoku no Kankei. [The effect of Follow-up on Listening Comprehension]. STEP Bulletin, 4, 48-62.

Tamai, K. (1997). Shadowing no koka to chokai process niokeru ichizuke [The Effectiveness of Shadowing and Listening Process]. Current English Studies, 36, 105-116.

Tamai, K. (2002). On The Effects of Shadowing on Listening Comprehension - Keynote Lecture at the 3rd Annual Conference of JAIS. Interpretation Studies, 2, 178-192.

Toda, T., Okubo, M., Kamiyama, Y., Konishi, R., \& Fukui, K. (2012). Shadowing de Nihongohatsuon Lesson (Japanese Pronunciation Practice through Shadowing). Tokyo: 3A Corporation.

Tseng, W., Dornyei, Z., \& Schmidt, R. (2006). A New Approach to Accessing Strategic Learning: The Case of SelfRegulation in Vocabulary Acquisition. Applied Linguistics, 27(1), 78-102.

Vallerand, R. (1997). Toward a Hierarchical Model of Intrinsic and Extrinsic Motivation. Advances in Experimental Social Psychology, 29, 271-360. doi:10.1016/50065-2601(08)60019-2.

Watanabe, A., Oba, R., Shimizu, T., Sugiyama, M., Nohara, Y., \& Sakuta, N. (2013). Japanese Language Proficiency Test N2 Complete Mock Exams. Tokyo: J Research Publisher. 